This document is confidential and is proprietary to the American Chemical Society and its authors. Do not copy or disclose without written permission. If you have received this item in error, notify the sender and delete all copies.

\title{
Thiol-dependent reduction of the triester and triamide derivatives of Finland trityl radical triggers 02 -dependent superoxide production
}

\begin{tabular}{|r|l|}
\hline Journal: & Chemical Research in Toxicology \\
\hline Manuscript ID & tx-2017-00086k.R2 \\
\hline Manuscript Type: & Article \\
\hline Date Submitted by the Author: & n/a \\
\hline Complete List of Authors: & $\begin{array}{l}\text { Tan, Xiaoli ; Tianjin Key Laboratory on Technologies Enabling Development } \\
\text { of Clinical Therapeutics and Diagnostics, School of Pharmacy, Tianjin } \\
\text { Medical University } \\
\text { Chen, Li; Tianjin Medical University, Tianjin Key Laboratory on } \\
\text { Technologies Enabling Development of Clinical Therapeutics and } \\
\text { Diagnostics, School of Pharmacy } \\
\text { Song, Yuguang; Tianjin Medical University, Pharmacy } \\
\text { Rockenbauer, Antal; Budapest University of Technology and Economics, } \\
\text { Department of Physics, MTA-BME Condensed Matter Research Group } \\
\text { Villamena, Frederick; Ohio State University, Pharmacology } \\
\text { Zweier, Jay; The Ohio State University Medical Center , DHLRI } \\
\text { Liu, Yangping; Tianjin Medical University, School of Pharmacy }\end{array}$ \\
\hline
\end{tabular}




\title{
Thiol-dependent reduction of the triester and triamide derivatives of Finland trityl radical triggers $\mathrm{O}_{2}$-dependent superoxide production
}

\begin{abstract}
Xiaoli Tan, ${ }^{\dagger}$ Li Chen, ${ }^{\dagger}$ Yuguang Song, ${ }^{*}{ }^{\dagger}$ Antal Rockenbauer, ${ }^{\#}$ Frederick A. Villamena, ${ }^{\S}$ Jay L. Zweier, ${ }^{\dagger}$ Yangping Liu ${ }^{*}, \dagger$

${ }^{\dagger}$ Tianjin Key Laboratory on Technologies Enabling Development of Clinical Therapeutics and Diagnostics, School of Pharmacy, Tianjin Medical University, Tianjin 300070, P. R. China

${ }^{\ddagger}$ Center for Biomedical EPR Spectroscopy and Imaging, The Davis Heart and Lung Research Institute, the Division of Cardiovascular Medicine, Department of Internal Medicine, The Ohio State University, Columbus, Ohio 43210, United States

${ }^{\S}$ Department of Biological Chemistry and Pharmacology, College of Medicine, The Ohio State University, Columbus, Ohio 43210, United States

"Institute of Materials and Environmental Chemistry, Hungarian Academy of Sciences and, Department of Physics, Budapest University of Technology and Economics, Budafoki ut 8, 1111 Budapest, Hungary
\end{abstract}

Corresponding authors: Yangping Liu and Yuguang Song

Email Address: liuyangping@tmu.edu.cn;

songyuguang@tmu.edu.cn.

Phone: 86-022-83336823 (Office) 


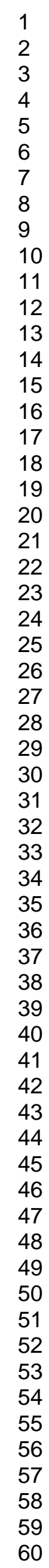

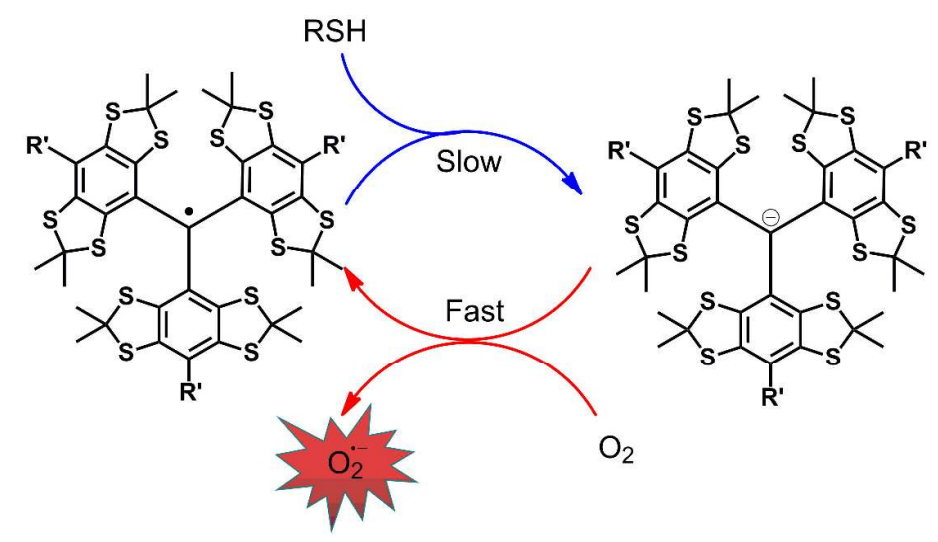




\section{Abstract}

Tetrathiatriaylmethyl (trityl) radicals have found wide biomedical applications as magnetic resonance probes. Trityl radicals and their derivatives are generally stable towards biological reducing agents such as glutathione (GSH) and ascorbate. We demonstrate that the triester (ET-03) and triamide (AT-03) derivatives of Finland trityl radical exhibit unique reduction by thiols such as GSH and cysteine (Cys) to generate the corresponding trityl carbanions as evidenced by the loss of EPR signal and appearance of characteristic UV-Vis absorbance at $644 \mathrm{~nm}$ under anaerobic conditions. The trityl carbanions can be quickly converted back to the original trityl radicals by oxygen $\left(\mathrm{O}_{2}\right)$ in air, thus rendering the reaction between the trityl derivative and biothiol undetectable under aerobic conditions. The reduction product of $\mathrm{O}_{2}$ by the trityl carbanions was shown to be superoxide radical $\left(\mathrm{O}_{2}{ }^{-}\right)$by EPR spin-trapping. Kinetic studies showed that the reaction rate constants $(k)$ depend on types of both trityl radicals and thiols with the order of $k_{\mathrm{ET}-03 / \mathrm{Cys}}\left(0.336 \mathrm{M}^{-1} \mathrm{~s}^{-1}\right)>k_{\mathrm{ET}-03 / \mathrm{GSH}}(0.070$ $\left.\mathrm{M}^{-1} \mathrm{~s}^{-1}\right)>k_{\mathrm{AT}-03 / \mathrm{Cys}}\left(0.032 \mathrm{M}^{-1} \mathrm{~s}^{-1}\right)>k_{\mathrm{AT}-03 / \mathrm{GSH}}\left(0.027 \mathrm{M}^{-1} \mathrm{~s}^{-1}\right)$. The reactivity of trityl radicals with thiols is closely related to the para-substituents of trityl radicals as well as the pKa of the thiols and is further reflected by the rate of $\mathrm{O}_{2}{ }^{--}$production and consumptions of $\mathrm{O}_{2}$ and thiols. This novel reaction represents a new metabolic process of trityl derivatives and should be considered in design and application of new trityl radical probes.

Key words: trityl radical; superoxide; electron paramagnetic resonance (EPR); spin trapping; thiol; glutathione; cysteine 


\section{Introduction}

Tetrathiatriarylmethyl (trityl, TAM) radicals such as CT-03 (also named as Finland trityl radical, Chart 1) and Ox063 have recently received much attention because of their unique properties of high biostability, water solubility, very sharp electron paramagnetic resonance (EPR) single line as well as long relaxation times. ${ }^{1,2}$ Due to these outstanding properties, trityl radicals have found wide applications in EPR spectroscopy and imaging, ${ }^{3,4}$ dynamic nuclear polarization (DNP) $)^{1,5,6}$ as well as Overhauser- enhanced MRI (OMRI). ${ }^{7,8}$ The great interest in trityl radicals has also stimulated effort to develop efficient approaches for their synthesis and derivatization, and the resulting compounds with improved properties enable new applications. The trityl derivatives are mostly based on CT-03 owing to its well-established synthetic procedures. $^{2,9,10}$ For example, the esterification ${ }^{9,11-14}$ and amidation ${ }^{15-17}$ of the carboxylic acid(s) in CT-03 endow them with high stability, intracellular targeting and enhanced oxygen sensitivity. Using similar strategies, trityl spin labels for proteins ${ }^{18,}$ ${ }^{19}$ and nucleic acids ${ }^{20}$ as well as trityl-nitroxide biradicals as redox probes ${ }^{21}$ and efficient polarizing agents for high-field dynamic nuclear polarization ${ }^{22}$ were also developed.

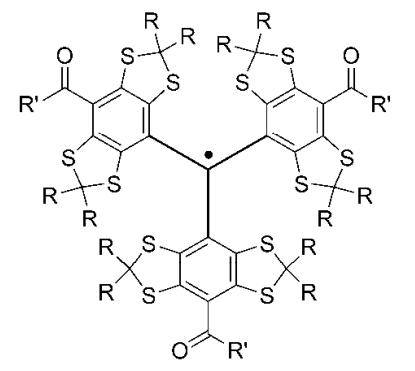

CT-03 $\mathrm{R}=\mathrm{CH}_{3}, \mathrm{R}^{\prime}=\mathrm{OH}$

OX063 R $=\mathrm{CH}_{2} \mathrm{CH}_{2} \mathrm{OH}, \mathrm{R}^{\prime}=\mathrm{OH}$

ET-03 R $=\mathrm{CH}_{3}, \mathrm{R}^{\prime}=\mathrm{OCH}_{2} \mathrm{C}(\mathrm{O}) \mathrm{OH}$

AT-03 $\mathrm{R}=\mathrm{CH}_{3}, \mathrm{R}^{\prime}=\mathrm{NHCH}_{2} \mathrm{C}(\mathrm{O}) \mathrm{OH}$ 


\section{Chart 1. Molecular structure of various trityl radicals.}

It has been long established that CT-03 and OX063 exhibit extraordinary stability towards biological oxidoreductants such as glutathione (GSH), ascorbate, hydrogen peroxide and hydroxyl radical, ${ }^{16,23}$ except for their specific reactivity with superoxide radical $\left(\mathrm{O}_{2}{ }^{\circ}\right)$. Owing to this unique reactivity, these trityl radicals have been used to detect $\mathrm{O}_{2}{ }^{--}$in various systems. ${ }^{23-25}$ Recently, a series of important studies from Boucher's group ${ }^{13,26-28}$ has demonstrated that these two radicals and their ester derivatives can undergo enzyme-mediated oxidation and reduction to the corresponding quinone methide and triarylmethane, respectively. However, to date there has been no report on direct reaction of trityl radicals with small-molecule biothiols such as GSH. Glutathione has been accepted to be one of the most critical substrates in the processes of nonenzymatic metabolisms of most drugs.

In the present study, we demonstrate for the first time that the triester (ET-03, Chart 1) and triamide (AT-03) derivatives of CT-03 can readily react with GSH and cysteine to generate the corresponding carbanions which further reduce $\mathrm{O}_{2}$ under aerobic conditions to $\mathrm{O}_{2}^{--}$, accompanying with recovery of the trityl derivatives. In contrast, CT-03 is inert to these biothiols. The reaction rate constants of ET-03 and AT-03 with the biothiols were determined under anaerobic conditions. Redox potentials of ET-03 and AT-03 were measured by cyclic voltammetry. Moreover, effects of types of both trityl radicals and thiols on the generation of $\mathrm{O}_{2}{ }^{\circ}, \mathrm{O}_{2}$ and thiol consumptions were also investigated. Based on the results obtained, the reaction 
mechanism between the trityl derivatives and biothiols under aerobic conditions was proposed. This new reaction mechanism should be considered in biomedical applications of trityl derivatives and may account for their potential toxicity in biological systems. Therefore, there is a great need to develop new strategies for derivatization of trityl radicals which prevent the generation of $\mathrm{O}_{2}{ }^{--}$but without compromising their excellent properties.

\section{Material and methods}

Reagents

Glutathione (GSH), cysteine (Cys), dimethyl sulfoxide (DMSO), diethylenetriaminepentaacetic acid (DTPA), superoxide dismutase (SOD) from bovine erythrocytes and 5,5'-Dithiobis-(2-nitrobenzoic acid) (DTNB) were purchased from Sigma-Aldrich. 5,5-Dimethyl-1-pyrroline N-oxide (DMPO) was purchased from Dojindo Molecular Technologies. Trityl radicals CT- $03^{9}$ and ET- $03^{12}$ were synthesized as previously described. 5-Tert-butoxycarbonyl-5-methyl-1-pyrroline N-oxide (BMPO) was synthesized using the previous reported method. ${ }^{29}$ The concentration of trityl radicals used in this study was determined by EPR using the purified CT-03 as standard. Phosphate buffer (PB, $200 \mathrm{mM}, \mathrm{pH}$ 7.4) was prepared from sodium dihydrogen phosphate and disodium hydrogen phosphate in the presence of DTPA $(400 \mu \mathrm{M})$. Unless otherwise indicated, PB containing DTPA was used throughout our study. Stock solutions $(1 \mathrm{mM})$ of trityl radicals as carboxylate sodium forms were prepared in phosphate buffer $(\mathrm{PB})$ and stored at $-20{ }^{\circ} \mathrm{C}$, whereas the solutions of GSH 
$(10 \mathrm{mM})$ and Cys $(10 \mathrm{mM})$ in PB were freshly prepared each day. All other chemicals were commercially available unless otherwise indicated.

\section{Synthesis of ET-03}

To the solution of CT-03 (50 mg, $0.05 \mathrm{mmol})$, in dry DMF $(5 \mathrm{ml})$ was added $N, N$-diisopropylethylamine (DIPEA, $40 \mu \mathrm{L}, 0.21 \mathrm{mmol}$ ) under $\mathrm{N}_{2}$. The reaction mixture was stirred at room temperature for $2 \mathrm{~min}$ and then excess of tert-butyl bromoacetate $(30 \mu \mathrm{L}, 0.21 \mathrm{mmol})$ was added. The resulting mixture was continuously stirred for $12 \mathrm{~h}$ at room temperature. Citric acid solution $(6 \%, 30 \mathrm{~mL})$ and ethyl acetate $(30 \mathrm{~mL})$ were added to quench the reaction. The organic layer was washed with brine $(3 \times 30 \mathrm{~mL})$, dried on anhydrous $\mathrm{Na}_{2} \mathrm{SO}_{4}$ and concentrated under vacuum. The tert-butyl ester form of ET-03 was purified by column chromatography on silica gel using hexane:ethyl acetate $=100: 5$ to $100: 10$ as eluents. The resulting brown solid was further treated with TFA overnight. The solvent was then removed under vacuum, and the residue was dissolved in PB (0.2 M, pH 7.4) and purified by reverse phase C-18 column chromatography using water followed by $0-20 \%$ methanol in water as eluents to give ET-03 as a brown-yellow solid (47 mg, 75\%). Purity: 95\% by HPLC with a retention time of $8.48 \mathrm{~min}$ (See Figure S1 in Supplementary Information). HRMS (High resolution mass spectrum, $\left[\mathrm{M}+\mathrm{H}_{2} \mathrm{O}\right]^{+}, \mathrm{m} / \mathrm{z}$ ): 1190.9882 (measured, Figure S2), 1190.9713(calculated).

Synthesis of AT-03 
To the solution of CT-03 (200 mg, $0.2 \mathrm{mmol}$ ), 1-hydroxybenzotriazole (HOBt, 162 $\mathrm{mg}, \quad 1.2 \mathrm{mmol}$ ) and (benzotriazol-1-yloxy)tris(dimethylamino)phosphonium hexafluoro- phosphate (BOP, $530 \mathrm{mg}, 1.2 \mathrm{mmol})$ in dry DMF $(20 \mathrm{ml})$ was added DIPEA $(200 \mu \mathrm{L})$ under $\mathrm{N}_{2}$. The reaction mixture was stirred at room temperature for $20 \mathrm{~min}$ and then excess of glycine tert-butyl ester hydrochloride (150 mg, $1.2 \mathrm{mmol}$ ) was added as solid. The resulting mixture was continuously stirred for $18 \mathrm{~h}$ at room temperature. Citric acid solution $(6 \%, 30 \mathrm{~mL})$ and ethyl acetate $(30 \mathrm{~mL})$ were added to quench the reaction. The organic layer was washed with brine $(3 \times 30 \mathrm{~mL})$, dried on anhydrous $\mathrm{Na}_{2} \mathrm{SO}_{4}$ and concentrated under vacuum. The tert-butyl ester form of AT-03 was purified by column chromatography on silica gel using hexane:ethyl acetate $=100: 5$ to $100: 10$ as eluents. The resulting brown solid was further treated with TFA overnight. The solvent was then removed under vacuum, and the residue was dissolved in $\mathrm{PB}(0.2 \mathrm{M}, \mathrm{pH} 7.4)$ and purified by reverse phase $\mathrm{C}-18$ column chromatography using water followed by $0-20 \%$ methanol in water as eluents to give AT-03 as a brown-green solid (178 mg, 72\%). Purity: 96\% by HPLC with a retention time of 9.59 min (See Figure S1 in Supplementary Information). HRMS ([M-H]', m/z): 1168.9875 (measured, Figure S2), 1168.9966 (calculated).

\section{EPR spectroscopy}

EPR measurements were carried out on Bruker EMX-plus X-band spectrometer at room temperature. General instrumental settings were as follows: modulation frequency, 30-100 kHz; microwave power, 0.05-10 $\mathrm{mW}$; modulation amplitude, 
0.01-0.5 G. Measurements were performed in $50 \mu \mathrm{L}$ capillary tubes. Spectral simulation was performed by the program developed by professor Rockenbauer. ${ }^{30}$ The reported hyperfine splitting constants of the spin adducts of BMPO were used as initial parameters for spectral simulations (see Table S1). The hyperfine splitting constants obtained by the simulation were well consistent with the reported values. ${ }^{29}$

As described previously, ${ }^{9}$ EPR measurements under anaerobic conditions were carried out using a gas-permeable Teflon tube (i.d. $=0.8 \mathrm{~mm}$ ). Briefly, the reaction solution was transferred to the tube which was then sealed at both ends. The sealed sample was placed inside a quartz EPR tube with open ends. Argon gas was allowed to bleed into the EPR tube and then EPR spectrum was recorded.

\section{Cyclic Voltammetry}

Cyclic voltammetry was performed on a potentiostat and computer-controlled electroanalytical system. Electrochemical measurements were carried out in a $10 \mathrm{~mL}$ cell equipped with a glassy carbon working electrode $\left(7.07 \mathrm{~mm}^{2}\right)$, a platinum-wire auxiliary electrode and a $\mathrm{Ag} / \mathrm{AgCl}$ reference electrode. Solutions of trityl radicals $(0.5$ $\mathrm{mM}$ ) were degassed by bubbling with the nitrogen gas before the detection. The redox potentials were calculated according to the relation $E=\left(E_{\mathrm{p}}^{\mathrm{a}}+E_{\mathrm{p}}^{\mathrm{c}}\right) / 2$.

\section{Oxygen consumption}

The $\mathrm{O}_{2}$ consumption was measured by EPR as previously described. ${ }^{24}$ The solution containing trityl radical and thiol was transferred to a $50 \mu \mathrm{L}$ capillary tube which was 
immediately sealed at both ends with cares to avoid any incorporation of bubble inside. Then, EPR spectra were continuously recorded with a period of up to 12 hours. The $\mathrm{O}_{2}$ sensitivity of trityl radicals was obtained according to their peak-to-peak linewidths under aerobic and anaerobic conditions as previously described. ${ }^{9}$ Then, the $\mathrm{O}_{2}$ concentration at each time point was calculated based on the measured peak-to-peak linewidth and $\mathrm{O}_{2}$ sensitivity of trityl radical (See details in Figure S4). All the experiments were repeated three times and the average rates of $\mathrm{O}_{2}$ consumption in the reaction system of trityl radicals with thiols were shown in Table 2.

Detection of the trityl carbanion of ET-03 by UV-Vis spectroscopy Reactions were monitored at room temperature using a U-3900 UV-Vis spectrophotometer in 1-cm path length quartz cuvette which was pre-purged with argon and stoppered with a rubber septum. A solution of ET-03 $(50 \mu \mathrm{M})$ in degassed PB $(50 \mathrm{mM}, \mathrm{pH} 7.4)$ was mixed with GSH $(500 \mu \mathrm{M})$ or sodium dithionite $(100 \mu \mathrm{M})$ under anaerobic conditions and UV-Vis spectra were collected immediately to monitor the generation of the trityl carbanion. ${ }^{13}$ To recover the trityl radical from its carbanion, air was bubbled to the above anaerobic solution for $3 \mathrm{~min}$. Of note is that ET-03 was only partially reduced under these conditions. Complete reduction of ET-03 $(50 \mu \mathrm{M})$ was achieved in the presence of high concentration of sodium dithionite $(500 \mu \mathrm{M})$ under anaerobic conditions (Figure S9). 


\section{Detection of $\mathrm{O}_{2}^{--}$by EPR-spin trapping technique}

The production of $\mathrm{O}_{2}{ }^{--}$was determined by EPR spin-trapping method. GSH (2 mM) was added to the solution containing ET-03 $(50 \mu \mathrm{M})$ or AT-03 $(50 \mu \mathrm{M})$ and the spin trap BMPO $(50 \mathrm{mM})$ in PB and then EPR spectra were recorded 105s later. While SOD $(200 \mathrm{U} / \mathrm{mL})$ was used to confirmed the production of $\mathrm{O}_{2}{ }^{--}$in the reaction system, DMSO $(2 \%, \mathrm{v} / \mathrm{v})$ was used as an efficient $\mathrm{HO}^{\bullet}$ scavenger to check if $\mathrm{HO}^{\bullet}$ was involved in the system since it can effectively scavenge $\mathrm{HO}^{\circ}$ to generate the secondary methyl radical which can be further trapped by BMPO to result in the methyl spin adduct.

\section{Measurement of the relative $\mathrm{O}_{2}{ }^{--}$levels by spin trapping}

The well characterized nitrone spin trap DMPO was used..$^{31}$ Thiol $(2 \mathrm{mM})$ was added to the solution containing trityl radical $(50 \mu \mathrm{M})$ and DMPO $(100 \mathrm{mM})$ in PB and then EPR spectra were recorded after 2-min incubation. The double integration of the low-field peak of each EPR signal was used to measure the relative $\mathrm{O}_{2}{ }^{\circ-}$ levels (Figure 4). In addition, the relative $\mathrm{O}_{2}{ }^{--}$levels were also determined by EPR simulation (see Table S2). Very similar results were obtained for both methods.

Kinetic studies of the reaction of trityl radicals with thiols under anaerobic conditions

Trityl radical $(50 \mu \mathrm{M})$ was mixed with various concentrations of thiols $(0.5 \mathrm{mM}$, $1 \mathrm{mM}, 2 \mathrm{mM}$ ) in $\mathrm{PB}$ and the resulting solution was immediately transferred to a gas-permeable Teflon tube with both ends sealed. The sealed sample was then placed 
inside a quartz EPR tube with open ends. Argon gas was allowed to bleed into the EPR tube. After 4-min equilibrium incremental EPR spectra were recorded over 25 min. Since the thiol concentration used was in excess relative to the concentration of trityl radical $(50 \mu \mathrm{M})$, the reaction of trityl radical with the thiol compound follows pseudo first-order kinetics. Due to the relatively slow reaction, the initial decay rate of trityl radical was determined within 5-15 min. Data was plotted using the following equation:

$\ln [\mathrm{T}]=\ln [\mathrm{T}]_{0}-k_{\text {obs }} t$

where $[\mathrm{T}]_{0}$ is the initial concentration of trityl radical, $[\mathrm{T}]$ the concentration of trityl radical at each time point, and $k_{o b s}$ the apparent first-order rate constant. Second-order rate constants $(k)$ of trityl radicals with thiols were eventually determined by plotting $k_{o b s}$ with the thiol concentrations (Table 1) (See details in Figure S5).

Determination of thiol concentrations by UV-Vis spectroscopy

The Ellman's method was used to measure the concentration of thiols. ${ }^{32}$ Thiol (2 mM) was mixed with the solution of trityl radical $(80 \mu \mathrm{M})$ in $\mathrm{PB}$ at room temperature. After 1 hour, excess of the Ellman's agent DTNB (6 eq) was added to the solution and UV-vis spectrum was recorded after appropriate dilutions with PB. The concentration of thiol left in the system was calculated according to the absorbance at $412 \mathrm{~nm}$ using the reported molar absorption coefficient $\left(\varepsilon=14.15 \mathrm{mM}^{-1} \mathrm{~cm}^{-1}\right)$.

\section{Results}




\section{Reduction of trityl radicals by GSH}

As shown in Figure 1, ET-03 had a single sharp EPR line with a linewidth of $308 \mathrm{mG}$ under aerobic conditions and this signal did not show any decay after 30-min incubation with GSH under aerobic conditions (Figure 1A). It seems that no reaction occurs between ET-03 and GSH under this condition. However, when the capillary containing ET-03 and GSH in PB was sealed at both ends, the EPR line of ET-03 was gradually narrowed with the peak-to-peak linewidths decreasing from 308 to $255 \mathrm{mG}$ after 11-hour incubation (Figure 1B). Correspondingly, the $\mathrm{O}_{2}$ concentration was reduced from 260 to $98 \mu \mathrm{M}$ (see details for measurement of $\mathrm{O}_{2}$ concentrations in the section of Material and methods), indicating that $\mathrm{O}_{2}$ consumption occurred in the sealed capillary. The double integration of the EPR signals indicates $\sim 25 \%$ decay of ET-03 after 11-hour incubation in the sealed capillary (Figure 1C). Therefore, limiting access of $\mathrm{O}_{2}$ to the reaction system leads to the decay of ET-03 in the presence of GSH $(500 \mu \mathrm{M})$. To further verify the role of $\mathrm{O}_{2}$, we carried out the same reaction under anaerobic conditions. As shown in Figure 1D, complete removal of $\mathrm{O}_{2}$ from the reaction system induced a much faster decay of ET-03 with $\sim 23 \%$ decease (from 50 to $38.3 \mu \mathrm{M})$ of its signal only in 2 hours. Further increase of the incubation time (4.5 hours) led to further decay of ET-03 ( 53\%) (Figure S6). Kinetic studies showed that ET-03 had a half-life of $4.83 \pm 0.08 \mathrm{~h}$ under anaerobic conditions in the presence of GSH $(500 \mu \mathrm{M})$, compared with $21.49 \pm 0.03 \mathrm{~h}$ under aerobic conditions (Figure S7). . Interestingly, reoxygenation of the above anaerobic solution by air resulted in quick recovery of ET-03 (48.5 $\mu \mathrm{M}, 97 \%)$. These results consistently demonstrate that ET-03 
can react with GSH to generate a relatively stable diamagnetic species which can be recovered back to ET-03 by $\mathrm{O}_{2}$. Similarly, AT-03 $(50 \mu \mathrm{M})$ can also react with GSH $(500 \mu \mathrm{M})$ but has much weaker reactivity with a slight loss of AT-03 $(2.9 \mu \mathrm{M})$ as compared to $11.7 \mu \mathrm{M}$ for ET-03 under the similar condition (Figure 1D). The weaker reactivity of AT-03 towards GSH than ET-03 was further verified by comparing their half-life times with the values of $9.56 \pm 0.27 \mathrm{~h}$ for AT-03 and $4.83 \pm 0.08 \mathrm{~h}$ for ET-03 under anaerobic conditions. Surprisingly, CT-03 did not show any reactivity to GSH under the same condition (Figure 1D). The introduction of GSH (2 mM) did not result in any decay of CT-03 either (Data not shown).

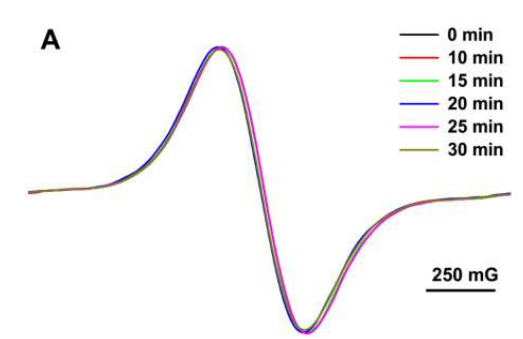

C

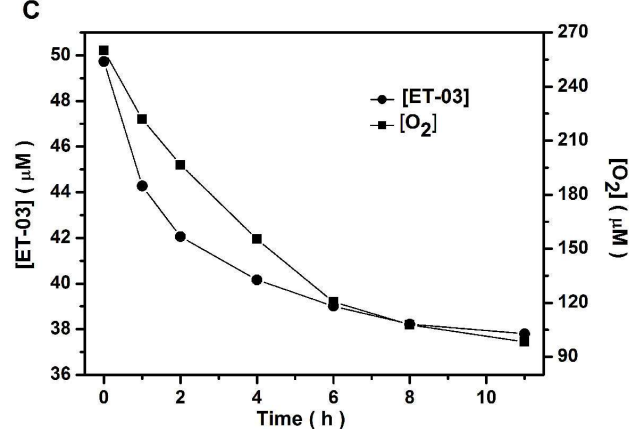

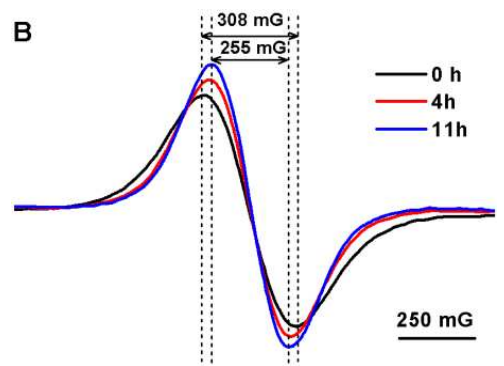

D

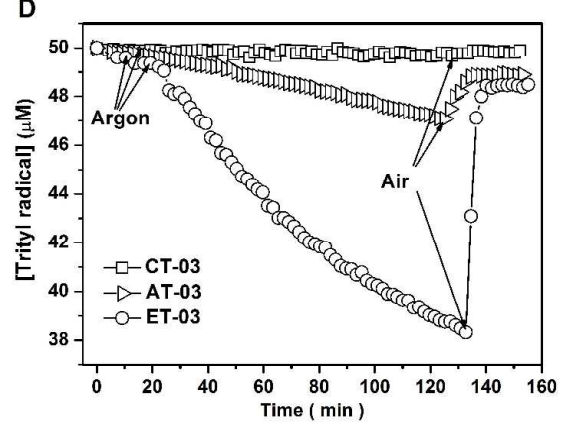

Figure 1 (A) EPR spectra of ET-03 $(50 \mu \mathrm{M})$ after incubation with GSH $(500 \mu \mathrm{M})$ in PB $(50 \mathrm{mM}$,

pH 7.4) for 0 - 30 min under aerobic conditions. (B) EPR spectra recorded from the solution of ET-03 $(50 \mu \mathrm{M})$ and GSH $(500 \mu \mathrm{M})$ in PB $(50 \mathrm{mM}, \mathrm{pH} 7.4)$ in a sealed capillary at the incubation time points of 0, 4, and 11 hours. (C) Plot of the concentrations of ET-03 (circle) and $\mathrm{O}_{2}$ (square) as a function of time in a sealed capillary containing ET-03 $(50 \mu \mathrm{M})$ and GSH $(500 \mu \mathrm{M})$ in PB $(50$ 
mM, pH 7.4). (D) Plot of concentrations of ET-03 (circle), AT-03 (triangle) and CT-03 (square) as a function of time after the reactions of each trityl radical $(50 \mu \mathrm{M})$ with GSH $(500 \mu \mathrm{M})$ in a gas-permeable tube which was passed through argon and then air.

\section{Redox potentials of trityl radicals}

Redox potentials of ET-03 and AT-03 were measured by cyclic voltammetry and compared with CT-03 to interpret their thermodynamic feasibility for reactions with GSH. As shown in Figure S8, both trityl radicals can undergo one-electron quasi-reversible reduction to the corresponding trityl carbanion and one-electron reversible oxidation to the carbocation form. Table 1 summarizes the oxidation and reduction potentials of trityl radicals. ET-03 (-0.309 V vs. $\mathrm{Ag} / \mathrm{AgCl})$ has much higher reduction potential than AT-03 (-0.459 V vs. $\mathrm{Ag} / \mathrm{AgCl})$ and $\mathrm{CT}-03(-0.624 \mathrm{~V}$ vs. $\mathrm{Ag} / \mathrm{AgCl}) .{ }^{33}$ As for the oxidation potentials, the opposite tendency was observed for these trityl radicals (Table 1). Replacement of the negatively charged carboxylates in CT-03 with the electron-withdrawing ester or amide groups led to higher reduction potentials for ET-03 and AT-03 than CT-03. Similar reduction and oxidation potentials were also reported for other ester and amide derivatives of trityl radicals. ${ }^{13 \text {, }}$

${ }^{17}$ Thus, from the thermodynamic point of view, the reduction of either ET-03 or AT-03 by GSH is more favorable than CT-03.

Table 1 Redox potentials of trityl radicals relative to $\mathrm{Ag} / \mathrm{AgCl}$ and their reaction rate constants with GSH $\left(k_{G S H}\right)$ and cysteine $\left(k_{c y s}\right)$ under anaerobic conditions, and $\mathrm{O}_{2}{ }^{-}{ }^{-}\left(k_{s p}\right)$ in $\mathrm{PB}(50 \mathrm{mM}, \mathrm{pH}$ 
7.4). See more details in the section of Material and methods.

\begin{tabular}{cccccc}
\hline Radicals & $E_{\text {red }}(\mathrm{V})$ & $E_{\text {ox }}(\mathrm{V})$ & $k_{G S H}\left(\mathrm{M}^{-1} \mathrm{~s}^{-1}\right)$ & $k_{c y s}\left(\mathrm{M}^{-1} \mathrm{~s}^{-1}\right)$ & $k_{s p}\left(\mathrm{M}^{-1} \mathrm{~s}^{-1}\right)$ \\
\hline CT-03 & -0.624 & 0.456 & No reaction & No reaction & $3.1 \times 10^{3}$ \\
AT-03 & -0.459 & 0.643 & $0.027 \pm 0.002$ & $0.032 \pm 0.004$ & No reaction \\
ET-03 & -0.309 & 0.733 & $0.070 \pm 0.002$ & $0.336 \pm 0.004$ & No reaction \\
\hline
\end{tabular}

Note: $k_{\mathrm{sp}}$ of CT-03 $\left(3.1 \times 10^{3} \mathrm{M}^{-1} \mathrm{~s}^{-1}\right)$ was reported previously in the reference. ${ }^{24}$

\section{Detection of the trityl carbanion of ET-03 by UV-Vis spectroscopy}

GSH is a relatively strong reducing agent which is a key component of cellular redox homeostasis. ${ }^{34}$ The relatively high reduction potentials of ET-03 and AT-03 imply that they may be reduced by GSH to the corresponding carbanions. To verify this hypothesis, we used UV-Vis spectroscopy to detect the trityl carbanion of ET-03. As illustrated in Figure 2, the reaction of ET-03 with GSH under anaerobic conditions led to appearance of a new absorbance at $644 \mathrm{~nm}$. In the previous study, ${ }^{13}$ an almost identical UV-vis absorbance $\left(\lambda_{\max }=644 \mathrm{~nm}\right)$ was also observed when the other trityl ester derivatives were reduced by sodium dithionate. One of the reduction products was determined by mass spectroscopy to be the corresponding trityl carbanion. ${ }^{13}$ Using sodium dithionite as a reducing agent, we also observed the absorbance at 644 $\mathrm{nm}$ from ET-03 but with higher intensity than that observed in the case of GSH (Figure 2). This implied that the reduction of ET-03 by either GSH or sodium dithionite led to the same product which was most likely assigned to its trityl carbanion. Increasing the concentration of sodium dithionite led to complete transformation of ET-03 into its carbanion with the strong absorbance at $644 \mathrm{~nm}$ and 
complete disappearance of the absorbance of ET-03 at $491 \mathrm{~nm}$ (Figure S9). Consistent with the above EPR results, aerating the anaerobic solution containing the reduction product of ET-03 effectively recovered ET-03 as evidenced by the increase of the absorption intensity at $491 \mathrm{~nm}$, accompanying with disappearance of the absorbance at $644 \mathrm{~nm}$ (Figure 2). As noted earlier, ${ }^{13}$ the trityl carbanion of ET-03 could be detected by mass spectrometry. However, our attempt was not successful due to leakage of air to the anaerobic solution of the carbanion, as seen from the change of the color of the solution from blue to light brown before its injection into the spectrometry.

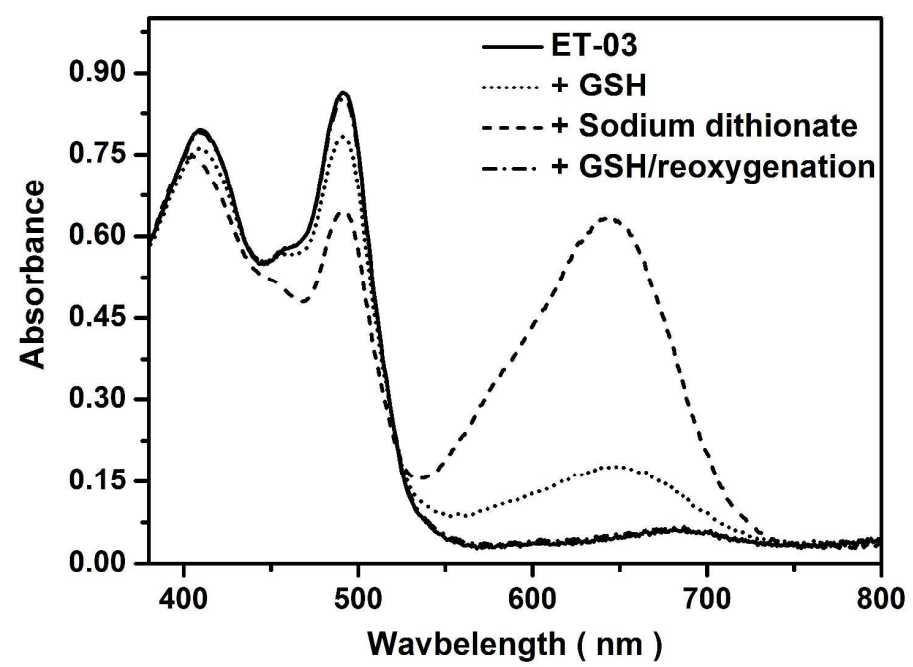

Figure 2 UV-Vis spectra of ET-03 $(50 \mu \mathrm{M})$ in aqueous solutions in the absence (solid line) or presence of GSH $(500 \mu \mathrm{M}$, dotted line) or sodium dithionate $(100 \mu \mathrm{M}$, dashed line) under anaerobic conditions as well as the spectrum (dash-dotted line which was overlapped with the solid line) obtained by aerating the solution which was pre-incubated for 30 min under anaerobic conditions. 


\section{Detection of $\mathrm{O}_{2}^{--}$by EPR-spin trapping technique}

As mentioned above, ET-03 and AT-03 can be effectively recovered from their carbanions by transferring one electron to $\mathrm{O}_{2}$. As such, we performed EPR-spin trapping experiments using BMPO as a spin trap to determine the reduction product of $\mathrm{O}_{2}$. Figure $3 \mathrm{~A}$ shows the vertically expanded EPR spectrum obtained from the solution of BMPO, ET-03 and GSH in PB (50 mM, pH 7.4). Due to the presence of the strong signal of ET-03, the signals of other paramagnetic species were not clearly seen in the non-expanded spectrum (Figure S10 in SI). EPR simulation (Figure 3B) indicates that this spectrum consists of three components which can be assigned to the superoxide $\left(\mathrm{BMPO} /{ }^{\circ} \mathrm{OOH}\right)$ and hydroxyl $\left(\mathrm{BMPO} /{ }^{\circ} \mathrm{OH}\right)$ spin adducts of $\mathrm{BMPO}$ as well as ET-03. Assignments of $\mathrm{BMPO} /{ }^{\circ} \mathrm{OOH}$ and $\mathrm{BMPO} /{ }^{\circ} \mathrm{OH}$ were based on the good agreement of their hyperfine splitting constants with the previously reported values (see Table $\mathrm{S} 1$ in $\mathrm{SI}) .^{29}$ The signals of $\mathrm{BMPO} /{ }^{\circ} \mathrm{OOH}$ and $\mathrm{BMPO} /{ }^{\circ} \mathrm{OH}$ were completely suppressed by SOD (200 U/ml, Figure 3C) with only the signal of ET-03 remaining, indicating that the signals of both spin adducts originate from $\mathrm{O}_{2}{ }^{\circ}$. In addition, neither $\mathrm{BMPO} /{ }^{\circ} \mathrm{OOH}$ nor $\mathrm{BMPO} /{ }^{\circ} \mathrm{OH}$ was observed in control experiments without any one of three agents (data not shown). The EPR signal of BMPO/OH could arise from direct trapping of ${ }^{\circ} \mathrm{OH}$ by $\mathrm{BMPO}$ or from the decomposition of $\mathrm{BMPO} /{ }^{\circ} \mathrm{OOH}$ in the presence of $\mathrm{GSH}^{35}$ To further verify the origin of $\mathrm{BMPO} /{ }^{\circ} \mathrm{OH}$, we used dimethyl sulfoxide (DMSO) as a highly efficient ${ }^{\circ} \mathrm{OH}$ scavenger. Hydroxyl radical, if any, can be detected by spin trapping of the secondary methyl radical formed in the reaction of OH with DMSO. Almost identical EPR spectra were observed in the presence 
(Figure 3D) or absence (Figure $3 \mathrm{~A}$ ) of $\mathrm{DMSO}$, indicating that $\mathrm{BMPO} /{ }^{\circ} \mathrm{OH}$ is most likely due to the decomposition of BMPO/OOH. ${ }^{35}$ Similarly, both spin adducts of BMPO were also observed from the solution containing AT-03, GSH and BMPO (Figure S11). Thus, the reduction of $\mathrm{O}_{2}$ by the trityl carbanions results in the production of $\mathrm{O}_{2}{ }^{-*}$.
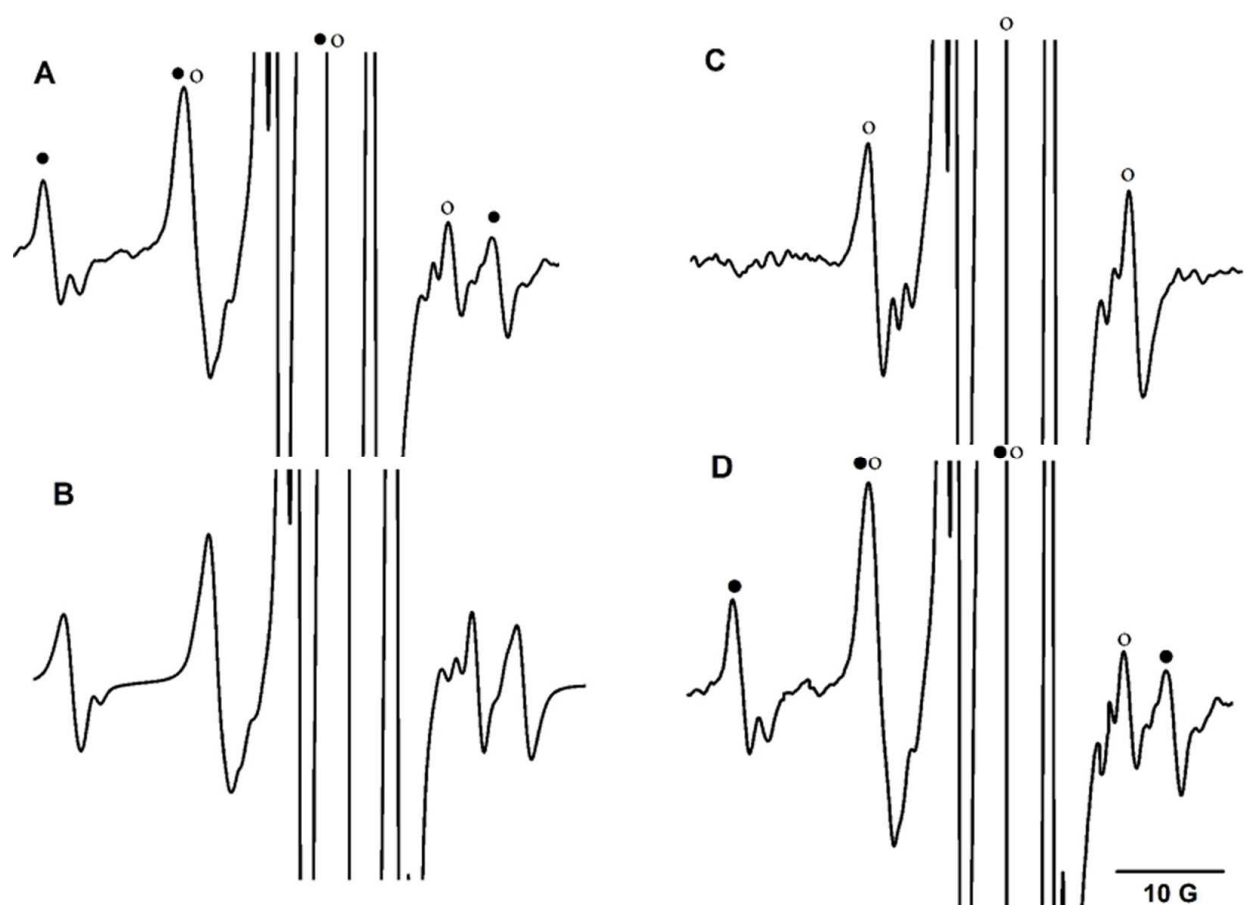

Figure 3 (A) EPR spectrum (15-fold enlargement as compared to the original spectra) obtained by addition of BMPO $(50 \mathrm{mM})$ to the solutions of ET-03 $(50 \mu \mathrm{M})$ and GSH $(2 \mathrm{mM})$ in PB $(50 \mathrm{mM}$, $\mathrm{pH}$ 7.4) in air. Note: (filled circle) the overlapped signals of superoxide (BMPO/OOH) and hydroxyl (BMPO/OH) spin adducts of BMPO; (unfilled circle) the signal of ET-03. (B) Computer simulation of the spectrum A. Hyperfine splitting constants used for EPR simulation were shown in Table S1 in SI. (C) Same as (A) but EPR spectrum was recorded in the presence of SOD (200 $\mathrm{U} / \mathrm{mL}$ ). The weak signals at both sides were attributed to the ${ }^{13} \mathrm{C}$ hyperfine splitting of the central 
carbon (23.5 G). (D) Same as (A) but EPR spectrum was recorded in the presence of DMSO (2\%, $\mathrm{v} / \mathrm{v})$.

\section{Reactivity of trityl radicals with thiols}

In order to quantitatively describe the reactivity of trityl radicals with thiols, their second-order rate constants were measured by EPR under anaerobic conditions where the $\mathrm{O}_{2}$-induced recovery of trityl radicals from the trityl carbanions was completely inhibited.. As shown in Table 1, ET-03 has the higher second-order rate constant $\left(0.070 \pm 0.002 \mathrm{M}^{-1} \mathrm{~s}^{-1}\right)$ with GSH than AT-03 $\left(0.027 \pm 0.002 \mathrm{M}^{-1} \mathrm{~s}^{-1}\right)$, whereas CT-03 is inert to GSH. The replacement of GSH by cysteine leads to 4.8- and 1.2-fold increases of the rate constants for ET-03 $\left(0.336 \pm 0.004 \mathrm{M}^{-1} \mathrm{~s}^{-1}\right)$ and AT-03 $(0.032 \pm$ $\left.0.004 \mathrm{M}^{-1} \mathrm{~s}^{-1}\right)$, respectively. High reactivity of ET-03 with thiols is closely associated with the strong electron-withdrawing character of the ester groups Meanwhile, since thiolate is the reactive form of thiol in redox reactions, higher reactivity of cysteine than GSH can be attributable to lower pKa (8.3) of the thiol group in cysteine than the latter $(8.8) .^{36}$

\section{Effect of trityl radicals and thiols on the generation of $\mathrm{O}_{2}{ }^{--}$}

Our above results showed that both ET-03 and AT-03 can be reduced by GSH into the corresponding trityl carbanions which further reduce $\mathrm{O}_{2}$ to $\mathrm{O}_{2}{ }^{\circ}$. It can be thus expected that the relative levels of $\mathrm{O}_{2}{ }^{\circ-}$ generated from these reaction systems are associated with the reactivity of trityl radicals with thiols. However, it has been shown 
that trityl radicals including CT-03 and OX063 can also react with $\mathrm{O}_{2}{ }^{-3} \cdot{ }^{37,24}$ Thus, evaluating the reactivity of both ET-03 and AT- 03 with $\mathrm{O}_{2}{ }^{--}$is prerequisite to measure the $\mathrm{O}_{2}{ }^{--}$levels generated in their reactions with biothiol. As shown in Figure S13, the characteristic UV-vis absorbance intensities of ET-03 at $484 \mathrm{~nm}$ or AT-03 at $462 \mathrm{~nm}$ remained to be almost identical before and after the introduction of $\mathrm{O}_{2}{ }^{--}$in the system. Moreover, the introduction of either ET-03 or AT-03 into the solution containing DMPO, xanthine and xanthine oxidase did not change the EPR signals (Figure S14). Thus, neither ET-03 nor AT-03 reacted with $\mathrm{O}_{2}{ }^{--}$. In other words, these two trityl derivatives do not consume $\mathrm{O}_{2}{ }^{--}$generated in their reactions with thiols.

Thereafter, the relative levels of $\mathrm{O}_{2}{ }^{--}$generated from the reactions of both ET-03 and AT-03 with thiols were measured by the EPR spin-trapping technique. The $\mathrm{O}_{2}{ }^{-}$ spin adduct of DMPO has a relatively short half-life time $\left(t_{1 / 2} \sim 1 \mathrm{~min}\right)$ and is gradually decomposed to the ${ }^{\circ} \mathrm{OH}$ spin adduct. Thus, the double integration of the low-field multiple peaks from both $\mathrm{O}_{2}{ }^{-}$and ${ }^{\circ} \mathrm{OH}$ spin adducts was used to measure the relative levels of $\mathrm{O}_{2}{ }^{--}$(Figure $\left.\mathrm{S} 15\right)$. As shown in Figure 4, the order of the relative EPR double integrations is ET-03/Cys (1.0) > ET-03/GSH (0.57) > AT-03/Cys $(0.46)>$ AT-03/GSH (0.31), consistent with the order of their rate constants (Table 1). Additionally, EPR simulation was carried out to quantitate the levels of $\mathrm{O}_{2}{ }^{--}$and similar results were obtained (Table S2). 


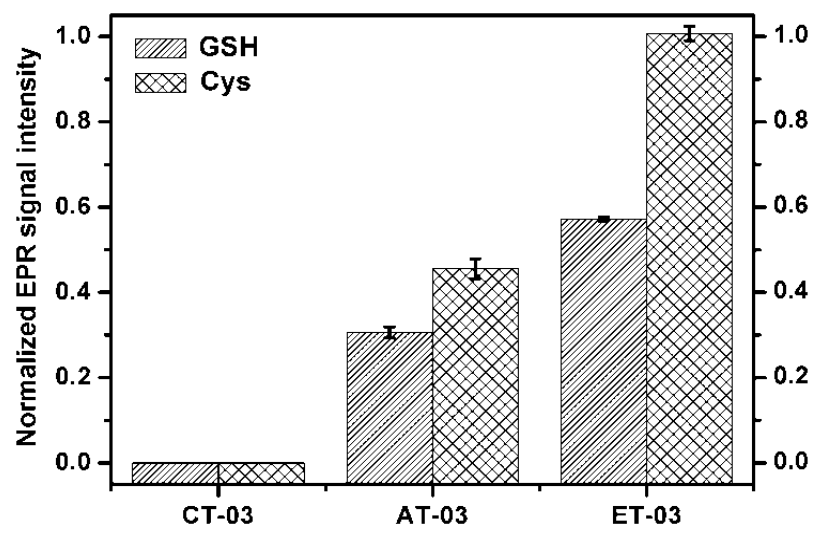

Figure 4 The relative EPR signal intensity of DMPO spin adducts which were generated by adding DMPO $(100 \mathrm{mM})$ to the solution of trityl radical $(50 \mu \mathrm{M})$ and thiol $(2 \mathrm{mM})$. The relative double integration of the low-field multiple peaks of each EPR signal was used.

\section{Effect of trityl radicals and thiols on the $\mathrm{O}_{2}$ consumption}

Since the EPR line width of trityl radicals exhibits good sensitivity to $\mathrm{O}_{2}$, the $\mathrm{O}_{2}$ consumption can be determined by monitoring the change in the line widths of trityl radicals. Figure 5 shows a plot of the consumed $\mathrm{O}_{2}$ concentrations versus time. A rapid $\mathrm{O}_{2}$ consumption was observed in the ET-03/Cys system with complete $\mathrm{O}_{2}$ consumption only in one and a half hours. Conversely, the relatively low $\mathrm{O}_{2}$ consumption was observed in the AT-03/GSH system in which the $\mathrm{O}_{2}$ consumption was not complete even after 12 hours. According to the data in Figure 5, the initial $\mathrm{O}_{2}$ consumption rate for each reaction system (Table 2) was calculated with the order of ET-03/Cys $\left(209.8 \pm 8.6 \mu \mathrm{M} \mathrm{O}_{2} / \mathrm{h}\right)>$ ET-03/GSH $\left(70.5 \pm 4.2 \mu \mathrm{M} \mathrm{O}_{2} / \mathrm{h}\right)>$ AT-03/Cys $\left(43.2 \pm 3.1 \mu \mathrm{M} \mathrm{O}_{2} / \mathrm{h}\right)>\operatorname{AT}-03 / \mathrm{GSH}\left(23.8 \pm 2.2 \mu \mathrm{M} \mathrm{O}_{2} / \mathrm{h}\right)$. 


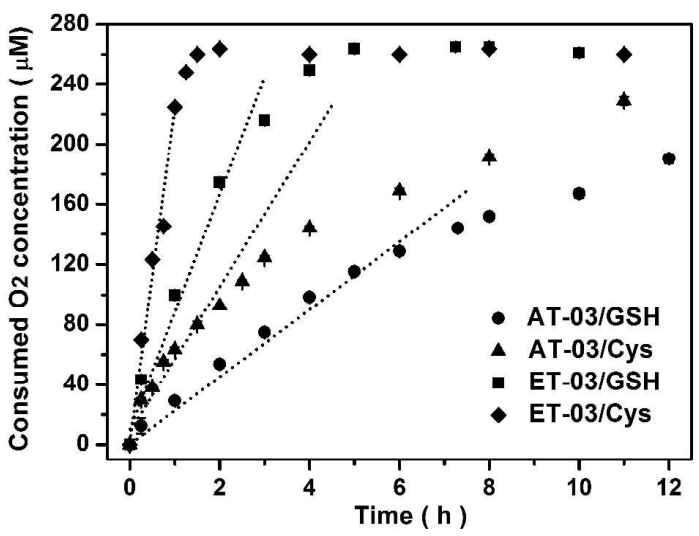

Figure 5 Plot of the consumed $\mathrm{O}_{2}$ concentration as a function of time in the sealed capillary containing trityl radical $(80 \mu \mathrm{M})$ and thiol $(2 \mathrm{mM})$ in PB $(\mathrm{pH} 7.4,50 \mathrm{mM})$; AT-03/GSH (circle), AT-03/Cysteine (triangle), ET-03/GSH (square), ET-03/Cysteine (rhombus). All the experiments were repeated three times and error bars are small in some cases and within the symbols.

Table $2 \mathrm{O}_{2}$ consumption rates $(\mu \mathrm{M} \mathrm{O} / \mathrm{h})$ in the sealed capillary containing trityl radical $(80 \mu \mathrm{M})$ with thiols $(2 \mathrm{mM})$ in $\mathrm{PB}(\mathrm{pH} 7.4,50 \mathrm{mM})$.

\begin{tabular}{ccc}
\hline Trityl radical & GSH & Cys \\
\hline AT-03 & $23.8 \pm 2.2$ & $43.2 \pm 3.1$ \\
ET-03 & $70.5 \pm 4.2$ & $209.8 \pm 8.6$ \\
\hline
\end{tabular}

\section{Effect of trityl radicals and thiols on the thiol consumption}

Figure 6 shows the thiol concentrations measured after the incubation of thiol with ET-03 or AT-03 for 1 hour in PB (pH 7.4, 50mM). No significant consumption of thiols was observed in the absence of the trityl radicals. Addition of the trityl radical to the solution of either GSH or cysteine in PB induced the thiol consumption. The concentrations of thiols remaining after 1-h incubation with the trityl radicals are 
closely related to types of trityl radicals and thiols: $1.85 \pm 0.02 \mathrm{mM}($ AT-03/GSH) $>$ $1.80 \pm 0.03 \mathrm{mM}($ AT-03/Cys $)>1.57 \pm 0.02 \mathrm{mM}($ ET-03/GSH $)>1.19 \pm 0.02 \mathrm{mM}$ (ET-03/Cys). The fast thiol consumption was observed for the system of ET-03/Cys with $40 \%$ of cysteine consumed during the period of 1 hour.

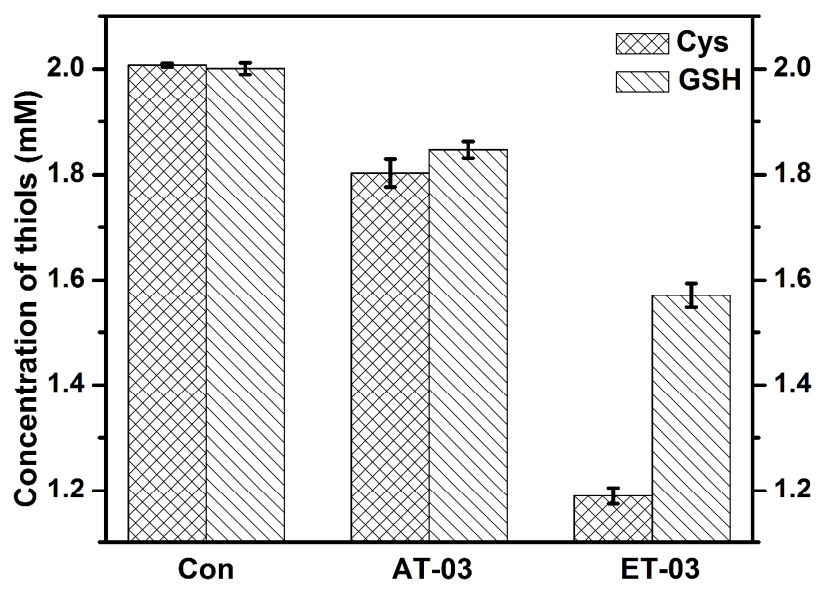

Figure 6 Thiol concentrations remaining after 1-h incubation with trityl radicals. Thiol (2 mM) was mixed with the solution of trityl radical $(80 \mu \mathrm{M})$ in $\mathrm{PB}(\mathrm{pH} 7.4,50 \mathrm{mM})$ at ambient atmosphere. After one hour, the thiol concentrations in different systems were determined using the Ellman's method.

\section{Discussion}

High stability of trityl radicals is the key feature accounting for their wide applications in magnetic resonance-related fields. It was previously shown that these radicals and their derivatives exhibit reactivity only towards some oxidants such as $\mathrm{O}_{2}{ }^{--}$, alkylperoxyl radicals or peroxides in the presence of redox enzymes. ${ }^{16,23,27,37}$ However, the direct reduction of trityl radicals by thiols was not previously reported, 
although the enzyme-mediated reduction of trityl radicals was observed in rat liver microsomes in the presence of NADPH. ${ }^{13,26}$ In this study, we demonstrate that the trityl derivatives ET-03 and AT-03 can be reduced by biothiols such as GSH and cysteine to form the corresponding trityl carbanions which can rapidly react with $\mathrm{O}_{2}$ in air to generate $\mathrm{O}_{2}{ }^{--}$with the recovery of the trityl derivatives.

Oxygen plays an important role in the reactions of both ET-03 and AT-03 with thiols. Under aerobic conditions, the reaction of ET-03 $(50 \mu \mathrm{M})$ with GSH $(500 \mu \mathrm{M})$ did not cause any significant change in its EPR signal intensity in half an hour (Figure 1A). However, limiting access of $\mathrm{O}_{2}$ to the reaction mixture in the sealed capillary leads to the gradual decay of ET-03 (Figure 1C). Complete removal of $\mathrm{O}_{2}$ from the reaction mixture (Figure 1D) induced a relatively faster decay of ET-03 with $\mathrm{t}_{1 / 2}=$ $4.83 \mathrm{~h}$ as compared to $\mathrm{t}_{1 / 2}=21.49 \mathrm{~h}$ under aerobic conditions (Figure S7). The direct evidence for the involvement of $\mathrm{O}_{2}$ stems from the $\mathrm{O}_{2}$ consumption in the reactions of the trityl derivatives with thiols (Figure $1 \mathrm{C}$ and 5, Table 2). Therefore, $\mathrm{O}_{2}$ is the "mask" to conceal the reactivity of trityl derivatives with thiols.

Interestingly, the reactivity with thiols is closely related to the substituents of the trityl radicals as well as pKa's of the thiol groups (Table 1). The order of their reaction rate constants is as follows: $k_{\mathrm{ET}-03 / \mathrm{Cys}}\left(0.336 \mathrm{M}^{-1} \mathrm{~s}^{-1}\right)>k_{\mathrm{ET}-03 / \mathrm{GSH}}\left(0.07 \mathrm{M}^{-1} \mathrm{~s}^{-1}\right)>$ $k_{\mathrm{AT}-03 / \mathrm{Cys}}\left(0.032 \mathrm{M}^{-1} \mathrm{~s}^{-1}\right)>k_{\mathrm{AT}-03 / \mathrm{GSH}}\left(0.027 \mathrm{M}^{-1} \mathrm{~s}^{-1}\right)$. While both ET-03 and AT-03 exhibit reactivity with thiols, CT-03 is inert to thiols under the similar condition. Cysteine with low pKa (8.3) has higher $k$ values with ET-03 and AT-03 than GSH (Table 1), implying that the thiolate is the reactive form of thiol in their oxidation 
reactions. In order to check if other reducing agents can also initiate the reduction of the trityl radicals, we also tested the reactivity of ET-03 $(50 \mu \mathrm{M})$ under anaerobic conditions with ascorbic acid $(10 \mathrm{mM})$ under anaerobic conditions which is a crucial reducing agent for the intracellular reduction of nitroxide radicals. However, no reaction was observed between them under our experimental conditions (Figure S17). Certainly, our present results do not exclude the susceptibility of trityl radicals to other reducing agents. In the previous studies, the reductive metabolism of trityl radicals (e.g., CT-03) and their ester derivatives under anaerobic conditions was observed in the presence of NADPH in rat liver microsomes. The direct reduction of the trityl radicals by NADPH may be also involved in this system.

The oxidation of the trityl carbanions by $\mathrm{O}_{2}$ resulted in the recovery of the corresponding trityl radicals (Figure 1D). However, it was reported previously that the trityl carbanions were also able to undergo protonation to the corresponding diamagnetic triarylmethane in the presence of water or other proton sources. ${ }^{13,26}$ Thus, the protonation of the trityl carbanions may compete with their oxidation by $\mathrm{O}_{2}$ in aqueous solution. Careful examination of the result in Figure 1D shows that both ET-03 and AT-03 have relatively high recovery efficiencies from their carbanions by $\mathrm{O}_{2}$ with the percentages of $87 \%[(48.5-38.3) \mu \mathrm{M} /(50-38.3) \mu \mathrm{M}]$ and $62 \%[(48.9-47.1)$ $\mu \mathrm{M} /(50-47.1) \mu \mathrm{M}]$, respectively, during the same period ( $\sim 2$ hours). Relatively efficient recovery of trityl radicals demonstrates that the oxidation reactions of both trityl carbanions by $\mathrm{O}_{2}$ instead of their protonations are predominant under aerobic conditions. That the trityl carbanions have low tendency for the protonation can be 
rationalized by the strong electron-withdrawing character of the ester/amide substituents which stabilizes the carbanions by efficient delocalization of the negative charges and further lowers pKa's of the corresponding triarylmethanes. As expected, the protonation of these trityl carbanions would be more significant in tumor or ischemic tissues where there are $\mathrm{pH}$ and $\mathrm{O}_{2}$ concentrations. ${ }^{38}$ On the other hand, considering that the trityl carbanions can be oxidized by $\mathrm{O}_{2}$ back to trityl radicals, the triarylmethanes may also react with $\mathrm{O}_{2}$ to result in the trityl radicals, provided that the triarylmethanes can be deprotonated to the corresponding carbanions in the presence of appropriate bases.

As mentioned above, the one-electron transfer of these trityl carbanions to $\mathrm{O}_{2}$ is the dominant route responsible for their decomposition. Thus, the $\mathrm{O}_{2}$ consumption rate (Table 2) and subsequent production of $\mathrm{O}_{2}{ }^{--}$(Figure 4) in the reaction systems should be correlated with the second-order rate constants of trityl radicals with thiols (Table 1). Considering that the electron transfer between the trityl carbanions and $\mathrm{O}_{2}$ is much faster than the reaction of trityl radical with thiols (Figure 1D), the production of the trityl carbanions is the rate-limiting step for the $\mathrm{O}_{2}$ consumption. However, the $\mathrm{O}_{2}$ consumption rate $(\sim 35 \mu \mathrm{M} / \mathrm{h}$ at the first 2 hours, Figure $1 \mathrm{C})$ in the reaction system of ET-03 with GSH is 6-fold higher than the decay rate of ET-03 $(\sim 6 \mu \mathrm{M} / \mathrm{h}$, Figure 1D), thus indicating that additional pathway(s) may be involved in the $\mathrm{O}_{2}$ consumption in this system. It has been shown that the cycle reaction among $\mathrm{O}_{2}, \mathrm{O}_{2}{ }^{--}$ and GSH greatly promotes the $\mathrm{O}_{2}$ consumption. ${ }^{36}$ Moreover, the fact that a large amount of thiols were consumed after incubation with the trityl radicals (Figure 6) 
further confirms that the thiol-involved cycle reaction exists in the trityl radical/thiol systems and the trityl radicals catalyze the consumption of the thiols. Therefore, trityl radical-catalyzed thiol and $\mathrm{O}_{2}$ consumptions as well as subsequent $\mathrm{O}_{2}{ }^{\circ-}$ production may arouse oxidative damage to biological systems and this adverse effect should be considered in their biomedical applications.

In summary, our results show that the ester and amide derivatives of CT-03 (i.e., ET-03 and AT-03) can be reduced by biothiols such as GSH and cysteine with the consumption of these biothiols, resulting in the production of the corresponding trityl cabanions which are relatively stable at neutral $\mathrm{pH}$ under anaerobic conditions but can be quickly recovered back by $\mathrm{O}_{2}$ in air to the trityl derivatives accompanied by the generation of $\mathrm{O}_{2}{ }^{--}$(Figure 7). An alternative mechanism may also involve $\mathrm{O}_{2}$ addition to the para position of one aromatic group to form the corresponding trityl peroxyl radical $^{39}$ that is further be reduced by thiol to the trityl hydroperoxide, followed by the release of ${ }^{\circ} \mathrm{OH}$ and the original trityl radical via homolytic cleavage of the $\mathrm{C}-\mathrm{O}$ bond. Since the carboxylic groups in CT-03 are the only modification sites, both esterification and amidation have already been its preferred derivatization strategies. ${ }^{9,}$ ${ }^{11-17}$ Although our observation was based on CT-03 and its derivatives, similar results would also be suitable for its hydrophilic analogue OX063 which has similar redox properties with CT-03. Our present study should be of significant importance at the following aspects: (1) this study demonstrates a new metabolic mechanism for these trityl derivatives and provides a warning for their in vivo applications due to the production of the potentially toxic $\mathrm{O}_{2}{ }^{--}$and the consumption of the thiol antioxidants. 
(2) The production of $\mathrm{O}_{2}{ }^{--}$and further reaction with thiols may partially deplete cysteines in proteins and thus reduce the labeling efficiency of proteins when using esterified trityl spin labels. ${ }^{40}$ (3) The thiol-dependent generation of $\mathrm{O}_{2}{ }^{--}$from the trityl derivatives may find applications in the treatment of cancers in which radical generation can be exploited to kill cancer cells. (4) This reaction also has to be considered for design of new trityl radicals as $\mathrm{O}_{2}{ }^{--}$probes since the generation of $\mathrm{O}_{2}{ }^{--}$ from trityl radicals themselves could interfere with the detection of this reactive species in biological systems. ${ }^{23-25}$ The covalent dendritic encapsulation of trityl radicals would be a feasible way to prevent their reactions with thiols. ${ }^{14,} 41$ Development of new dendritic trityl probes with high selectivity to $\mathrm{O}_{2}{ }^{-}$is underway.

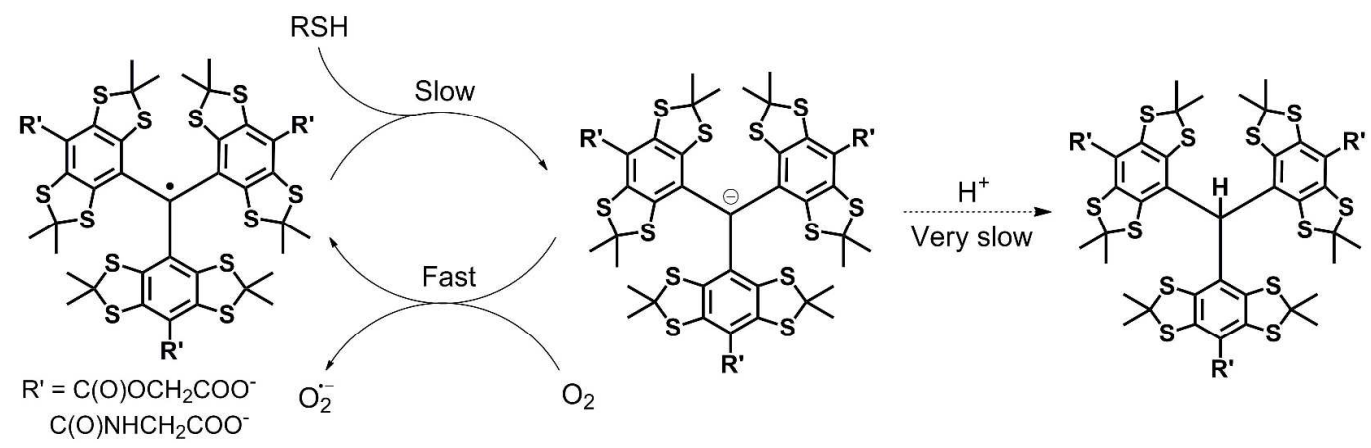

Figure 7 Reaction mechanism of trityl radical with thiol (RSH) under aerobic condition.

\section{Supporting Information}

HPLC chromatograms and high resolution mass spectra of ET-03 and AT-03; EPR spectra and the peak-to-peak linewidths of ET-03 and AT-03 under anaerobic and aerobic conditions; kinetic studies for the reactions of trityl radicals with thiols under anaerobic conditions; cyclic voltammograms of ET-03 and AT-03; UV-Vis analysis for 
the stability of ET-03 and AT-03 towards superoxide radicals; hyperfine splitting constants of the spin adducts of BMPO. This material is available free of charge via the Internet at http://pubs.acs.org.

\title{
Funding Sources
}

This work was partially supported by the National Natural Science Foundation of China (Nos. 21572161 and 31500684) and Science \& Technology Projects of Tianjin (Nos.15JCZDJC32300 and 15JCYBJC23700). The Hungarian National Research, Development and Innovation Office (NKFTH) Grant Nr. K119442 is acknowledged for support.

\begin{abstract}
ABBREVIATIONS
DMF, N,N-dimethylformamide; EPRI, electron paramagnetic resonance imaging; ESI, electrospray ionization; HRMS, highresolution mass spectrometry; DMSO, dimethyl sulfoxide; DTPA, diethylenetriaminepentaacetic acid; HOBt, 1-hydroxybenzotriazole; SOD, superoxide dismutase; DTNB, 5,5'-Dithiobis-(2-nitrobenzoic acid); GSH, Glutathione; Cys, cysteine; DMPO, 5,5-Dimethyl-1-pyrroline N-oxide; BMPO, 5-tert-Butoxycarbonyl-5-methyl-1-pyrroline $\mathrm{N}$-oxide; TAM, triarylmethyl radical. $\mathrm{O}_{2}{ }^{--}$, superoxide radical; ${ }^{\circ} \mathrm{OH}$, hydroxyl radical; $\mathrm{PB}$, phosphate buffer; DNP, dynamic nuclear polarization.
\end{abstract}

\section{References:}


(1) Ardenkjaer-Larsen, J. H., Laursen, I., Leunbach, I., Ehnholm, G., Wistrand, L. G., Petersson, J. S., and Golman, K. (1998) EPR and DNP properties of certain novel single electron contrast agents intended for oximetric imaging. J. Magn. Reson., 133, 1-12.

(2) Reddy, T. J., Iwama, T., Halpern, H. J., and Rawal, V. H. (2002) General synthesis of persistent trityl radicals for EPR imaging of biological systems. J. Org. Chem., 67, 4635-4639.

(3) Matsumoto, K., English, S., Yoo, J., Yamada, K., Devasahayam, N., Cook, J. A., Mitchell, J. B., Subramanian, S., and Krishna, M. C. (2004) Pharmacokinetics of a triarylmethyl-type paramagnetic spin probe used in EPR oximetry. Magn. Reson. Med., 52, 885-892.

(4) Elas, M., Ahn, K. H., Parasca, A., Barth, E. D., Lee, D., Haney, C., and Halpern, H. J. (2006) Electron paramagnetic resonance oxygen images correlate spatially and quantitatively with oxylite oxygen measurements. Clin. Cancer Res., 12, 4209-4217.

(5) Ardenkjaer-Larsen, J. H., Fridlund, B., Gram, A., Hansson, G., Hansson, L., Lerche, M. H., Servin, R., Thaning, M., and Golman, K. (2003) Increase in signal-to-noise ratio of $>10,000$ times in liquid-state NMR. Proc. Natl. Acad. Sci. USA, 100, 10158-10163.

(6) Gallagher, F. A., Kettunen, M. I., Day, S. E., Hu, D. E., Ardenkjaerlarsen, J. H., Ri, Z., Jensen, P. R., Karlsson, M., Golman, K., and Lerche, M. H. (2008) Magnetic resonance imaging of pH in vivo using hyperpolarized 13C-labelled bicarbonate. Nature, 453, 940-943.

(7) Krishna, M. C., English, S., Yamada, K., Yoo, J., Murugesan, R., Devasahayam, N., Cook, J. A., Golman, K., Ardenkjaer-Larsen, J. H., Subramanian, S., and Mitchell, J. B. (2002) Overhauser enhanced magnetic resonance imaging for tumor oximetry: Coregistration of tumor anatomy and tissue oxygen concentration. Proc. Natl. Acad. Sci. USA, 99, 2216-2221.

(8) Li, H. H., Deng, Y. M., He, G. L., Kuppusamy, P., Lurie, D. J., and Zweier, J. L. (2002) Proton electron double resonance imaging of the in vivo distribution and clearance of a triaryl methyl radical in mice. Magn. Reson. Med., 48, 530-534.

(9) Liu, Y., Villamena, F. A., Sun, J., Xu, Y., Dhimitruka, I., and Zweier, J. L. (2008) Synthesis and characterization of ester-derivatized tetrathiatriarylmethyl radicals as intracellular oxygen probes. $J$. Org. Chem., 73, 1490-1497.

(10) Rogozhnikova, O. Y., Vasiliev, V. G., Troitskaya, T. I., Trukhin, D. V., Mikhalina, T. V., Halpern, H. J., and Tormyshev, V. M. (2013) Generation of Trityl Radicals by Nucleophilic Quenching of Tris(2,3,5,6-tetrathiaaryl)methyl Cations and Practical and Convenient Large-Scale Synthesis of Persistent Tris(4-carboxy-2,3,5,6-tetrathiaaryl)methyl Radical. Eur. J. Org. Chem., 3347-3355.

(11) Liu, Y. P., Villamena, F. A., Sun, J., Wang, T. Y., and Zweier, J. L. (2009) Esterified trityl radicals as intracellular oxygen probes. Free. Radic. Biol. Med., 46, 876-883.

(12) Dhimitruka, I., Grigorieva, O., Zweier, J. L., and Khramtsov, V. V. (2010) Synthesis, structure, and EPR characterization of deuterated derivatives of Finland trityl radical. Bioorg. Med. Chem. Lett., 20, 3946-3949.

(13) Decroos, C., Balland, V., Boucher, J. L., Bertho, G., Yun, X. L., and Mansuy, D. (2013) Toward Stable Electron Paramagnetic Resonance Oximetry Probes: Synthesis, Characterization, and Metabolic Evaluation of New Ester Derivatives of a Tris-(para-carboxyltetrathiaaryl)methyl (TAM) Radical. Chem. Res. Toxicol., 26, 1561-1569.

(14) Song, Y. G., Liu, Y. P., Hemann, C., Villamena, F. A., and Zweier, J. L. (2013) Esterified Dendritic TAM Radicals with Very High Stability and Enhanced Oxygen Sensitivity. J. Org. Chem., 78, 1371-1376.

(15) Driesschaert, B., Leveque, P., Gallez, B., and Marchand-Brynaert, J. (2013) RGD-conjugated 
triarylmethyl radical as probe for electron paramagnetic imaging. Tetrahedron Lett., 54, 5924-5926.

(16) Liu, Y. P., Villamena, F. A., and Zweier, J. L. (2008) Highly stable dendritic trityl radicals as oxygen and $\mathrm{pH}$ probe. Chem. Commun., 4336-4338.

(17) Driesschaert, B., Bobko, A. A., Eubank, T. D., Samouilov, A., Khramtsov, V. V., and Zweier, J. L. (2016) Poly-arginine conjugated triarylmethyl radical as intracellular spin label. Bioorg. Med. Chem. Lett., 26, 1742-1744.

(18) Yang, Z. Y., Liu, Y. P., Borbat, P., Zweier, J. L., Freed, J. H., and Hubbell, W. L. (2012) Pulsed ESR Dipolar Spectroscopy for Distance Measurements in Immobilized Spin Labeled Proteins in Liquid Solution. J. Am. Chem. Soc., 134, 9950-9952.

(19) Yang, Z., Bridges, M. D., López, C. J., Rogozhnikova, O. Y., Trukhin, D. V., Brooks, E. K., Tormyshev, V., Halpern, H. J., and Hubbell, W. L. (2016) A triarylmethyl spin label for long-range distance measurement at physiological temperatures using $\mathrm{T} 1$ relaxation enhancement. J. Magn. Reson., 269, 50-54.

(20) Shevelev, G. Y., Krumkacheva, O. A., Lomzov, A. A., Kuzhelev, A. A., Rogozhnikova, O. Y., Trukhin, D. V., Troitskaya, T. I., Tormyshev, V. M., Fedin, M. V., Pyshnyi, D. V., and Bagryanskaya, E. G. (2014) Physiological-Temperature Distance Measurement in Nucleic Acid using Triarylmethyl-Based Spin Labels and Pulsed Dipolar EPR Spectroscopy. J. Am. Chem. Soc., 136, 9874-9877.

(21) Liu, Y., Villamena, F. A., Song, Y., Sun, J., Rockenbauer, A., and Zweier, J. L. (2010) Synthesis of $14 \mathrm{~N}-$ and $15 \mathrm{~N}-$ labeled Trityl-nitroxide Biradicals with Strong Spin-Spin Interaction and Improved Sensitivity to Redox Status and Oxygen. J. Org. Chem., 75, 7796-7802.

(22) Mathies, G., Caporini, M. A., Michaelis, V. K., Liu, Y. P., Hu, K. N., Mance, D., Zweier, J. L., Rosay, M., Baldus, M., and Griffin, R. G. (2015) Efficient Dynamic Nuclear Polarization at 800 MHz/527 GHz with Trityl-Nitroxide Biradicals. Angew. Chem. Int. Ed., 54, 11770-11774.

(23) Rizzi, C., Samouilov, A., Kutala, V. K., Parinandi, N. L., Zweier, J. L., and Kuppusamy, P. (2003) Application of a trityl-based radical probe for measuring superoxide. Free. Radic. Biol. Med., 35, 1608-1618.

(24) Liu, Y. P., Song, Y. G., De Pascali, F., Liu, X. P., Villamena, F. A., and Zweier, J. L. (2012) Tetrathiatriarylmethyl radical with a single aromatic hydrogen as a highly sensitive and specific superoxide probe. Free. Radic. Biol. Med., 53, 2081-2091.

(25) Driesschaert, B., Bobko, A. A., Khramtsov, V. V., and Zweier, J. L. (2016) Nitro-Triarylmethyl Radical as Dual Oxygen and Superoxide Probe. Cell Biochem. Biophys., 72, 241-246.

(26) Decroos, C., Li, Y., Bertho, G., Frapart, Y., Mansuy, D., and Boucher, J. L. (2009) Oxidative and Reductive Metabolism of Tris(p-carboxyltetrathiaaryl)methyl Radicals by Liver Microsomes. Chem. Res. Toxicol., 22, 1342-1350.

(27) Decroos, C., Li, Y., Soltani, A., Frapart, Y., Mansuy, D., and Boucher, J. L. (2010) Oxidative decarboxylation of tris-(p-carboxyltetrathiaaryl)methyl radical EPR probes by peroxidases and related hemeproteins: Intermediate formation and characterization of the corresponding cations. Arch. Biochem. Biophys., 502, 74-80.

(28) Decroos, C., Boucher, J. L., Mansuy, D., and Yun, X. L. (2014) Reactions of Amino Acids, Peptides, and Proteins with Oxidized Metabolites of Tris(p-carboxyltetrathiaaryl)methyl Radical EPR Probes. Chem. Res. Toxicol., 27, 627-636.

(29) Zhao, H., Joseph, J., Zhang, H., Karoui, H., and Kalyanaraman, B. (2001) Synthesis and biochemical applications of a solid cyclic nitrone spin trap: a relatively superior trap for detecting 
superoxide anions and glutathiyl radicals. Free. Radic. Biol. Med., 31, 599-606.

(30) Rockenbauer, A., and Korecz, L. (1996) Automatic computer simulations of ESR spectra. Appl. Magn. Reson., 10, 29-43.

(31) Villamena, F. A., and Zweier, J. L. (2004) Detection of reactive oxygen and nitrogen species by EPR spin trapping. Antioxid. Redox. Sign., 6, 619-629.

(32) Rootwelt, K. (1967) Quantitative determination of thiols and disulphides in urine by means of Ellman's reagent and thiolated Sephadex and its application in cystinuria. Scand. J. Clin. Lab. Inv., 19, 325-330.

(33) Liu, Y. P., Villamena, F. A., Rockenbauer, A., and Zweier, J. L. (2010) Trityl-nitroxide biradicals as unique molecular probes for the simultaneous measurement of redox status and oxygenation. Chem. Commun., 46, 628-630.

(34) Schafer, F. Q., and Buettner, G. R. (2001) Redox environment of the cell as viewed through the redox state of the glutathione disulfide/glutathione couple. Free. Radic. Biol. Med., 30, 1191-1212.

(35) Beziere, N., Hardy, M., Poulhes, F., Karoui, H., Tordo, P., Ouari, O., Frapart, Y. M., Rockenbauer, A., Boucher, J. L., Mansuy, D., and Peyrot, F. (2014) Metabolic stability of superoxide adducts derived from newly developed cyclic nitrone spin traps. Free. Radic. Biol. Med., 67, 150-158.

(36) Winterbourn, C. C., and Hampton, M. B. (2008) Thiol chemistry and specificity in redox signaling. Free. Radic. Biol. Med., 45, 549-561.

(37) Decroos, C., Li, Y., Bertho, G., Frapart, Y., Mansuy, D., and Boucher, J.-L. (2009) Oxidation of tris-(p-carboxyltetrathiaaryl)methyl radical EPR probes: evidence for their oxidative decarboxylation and molecular origin of their specific ability to react with $\mathrm{O}_{2}{ }^{\circ}$. Chem. Commun., 1416-1418.

(38) Rofstad, E. K. (2000) Microenvironment-induced cancer metastasis. Int. J. Radiat. Biol., 76, 589-605.

(39) Xia, S. J., Villamena, F. A., Hadad, C. M., Kuppusamy, P., Li, Y. B., Zhu, H., and Zweier, J. L. (2006) Reactivity of molecular oxygen with ethoxycarbonyl derivatives of tetrathiatriarylmethyl radicals. J. Org. Chem., 71, 7268-7279.

(40) Jassoy, J. J., Berndhauser, A., Duthie, F., Kuhn, S. P., Hagelueken, G., and Schiemann, O. (2017) Versatile Trityl Spin Labels for Nanometer Distance Measurements on Biomolecules In Vitro and within Cells. Angew. Chem. Int. Ed. Engl., 56, 177-181.

(41) Liu, W., Nie, J., Tan, X., Liu, H., Yu, N., Han, G., Zhu, Y., Villamena, F. A., Song, Y., Zweier, J. L., and Liu, Y. (2017) Synthesis and Characterization of PEGylated Trityl Radicals: Effect of PEGylation on Physicochemical Properties. J. Org. Chem., 82, 588-596. 